Research Article

\title{
An epidemiological survey to assess the clinical use of cephalosporins in community-acquired respiratory tract infections
}

\author{
Vikram Sobti*, K. Krishnaprasad, Amit Bhargava
}

Medical Services, Glenmark Pharmaceuticals Ltd., Mumbai - 400 099, Maharashtra, India

Received: 28 April 2015

Revised: 07 May 2015

Accepted: 10 May 2015

*Correspondence to:

Dr. Vikram Sobti,

Email: vikramsobti@yahoo. com

Copyright: (C) the author(s), publisher and licensee Medip Academy. This is an openaccess article distributed under the terms of the Creative Commons Attribution NonCommercial License, which permits unrestricted noncommercial use, distribution, and reproduction in any medium, provided the original work is properly cited.

\begin{abstract}
Background: In outpatient management of respiratory tract infections, the clinicians' preferences always have a broad spectrum of antibiotics as an empirical therapy. Clinical use of cephalosporins and fluoroquinolones has been recommended by various international guidelines as a monotherapy or as combination therapy to manage these. This survey was conducted to assess the in-clinic use and preference of cephalosporins or fluoroquinolones as monotherapy or as combination therapy in managing respiratory tract infections by Indian doctors.

Methods: A survey questionnaire was drafted to capture the feedback from crossspecialty regarding the preference of using antibiotics in respiratory tract infection in real time clinical settings.

Results: Data from 163 physicians were collected and evaluated across India. 79 (48\%) clinicians reported pharyngitis/tonsillitis to be the most commonly encountered respiratory tract infection followed by community-acquired pneumonia (CAP) 62 (38\%). 100 (61\%) clinicians preferred use of cefpodoxime monotherapy as a primary line of treatment for the management of respiratory pharyngitis/ tonsillitis. Use of short course therapy $(\leq 1$ week) of cefpodoxime and levofloxacin as combination therapy is preferred by $94(58 \%)$ clinicians, in cases of acute exacerbation of chronic bronchitis (AECB) 85 (52\%), and CAP 83 (51\%). The clinical preference of levofloxacin was observed with only $16(10 \%)$ clinicians, in lower respiratory tract infections, i.e. AECB and CAP.

Conclusion: In-clinic use of cefpodoxime as monotherapy is preferred in upper respiratory tract infections. However, clinicians recommend a combination therapy of cefpodoxime and levofloxacin in lower respiratory tract infections.
\end{abstract}

Keywords: Cephalosporins, Fluoroquinolones, Respiratory tract infections

\section{INTRODUCTION}

Respiratory tract infections (RTI) are among the most common infectious diseases in the community can occur in patients without any anatomic or functional abnormality. RTI, which includes both upper and lower respiratory tract infections, is not just a single disease rather a group of infections each with a different epidemiology, pathogenesis, clinical presentation and outcome. Acute respiratory infections (ARIs) may contribute to more than $75 \%$ of cases. ${ }^{1}$ Majority of these are of viral etiology, ${ }^{2}$ but prescribing antimicrobials for these illnesses is a common phenomenon in India.

There are guidelines recommendations available which recommend the use of antibiotics such as penicillin, $\beta$-lactams, fluoroquinolones, macrolides, etc., in ARIs. ${ }^{3-5}$ as prescribing antibiotics directed at the causative pathogen as early as possible in the course of infections is likely to improve the patient outcomes. Thus, the use of antibiotics as a monotherapy or combination therapy reasonably accepted by the clinicians. However, this often leads to overuse of antibiotic drugs, and a subsequent increase in adverse events, increased costs, and increase in antimicrobial resistance. ${ }^{6}$ This survey was designed to understand the preference of antibiotic by physicians in the treatment of ARIs in outdoor setup.

\section{METHODS}

This cross-specialty survey was conducted at 163 centers across the country, wherein a questionnaire was distributed among the clinicians seeking their feedback toward the preference of drugs as monotherapy or combination therapy, which is being used for treating adult patients being presented with ARIs including pharyngitis/tonsillitis, 
sinusitis, community-acquired pneumonia (CAP), and acute exacerbation of chronic bronchitis (AECB) in outdoor patient (OPD) setup.

The clinicians were asked to share the feedback of selecting cephalosporins, macrolides, fluoroquinolones or any other class of drugs of their choice in treating these acute respiratory cases in OPD. The data were requested of the patients who had no prior history hospitalization and were neither admitted failing to the oral antibiotic therapy especially in cases of CAP and AECB. Descriptive statistics was used to present the data.

\section{RESULTS}

A Total of 200 clinicians were enrolled in the survey, of which the data were received from 163 clinicians. The most frequently encountered clinical cases reported to be of tonsillitis and pharyngitis followed by AECB and CAP. However, 38\% of the clinicians reported all of these cases to frequently treated in their clinics as shown in Figure 1.

For the treatment of acute upper respiratory infections, the preferred choice of antibiotics was use of cefpodoxime as

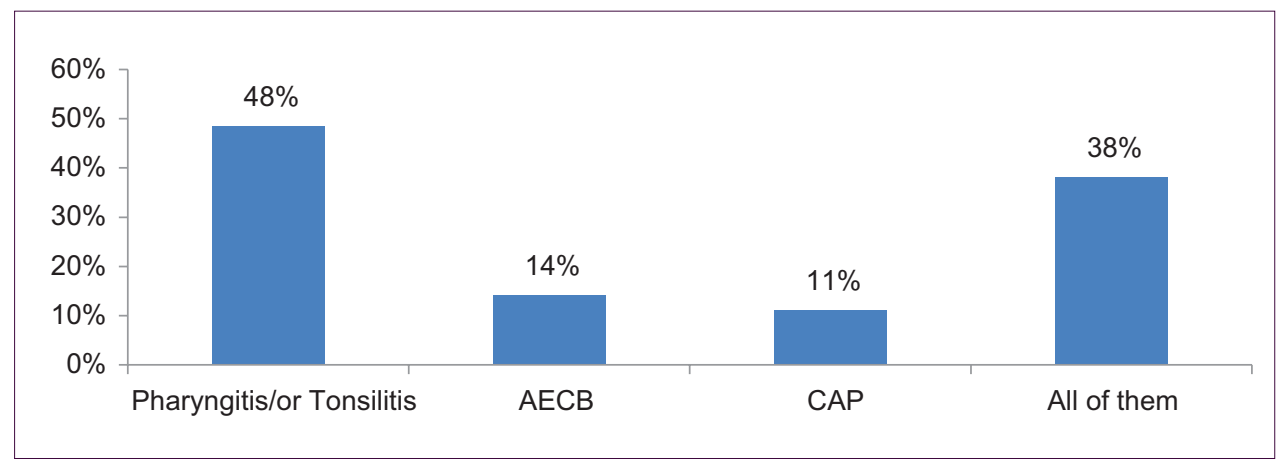

Figure 1: Observed in clinical practice acute respiratory tract infections.

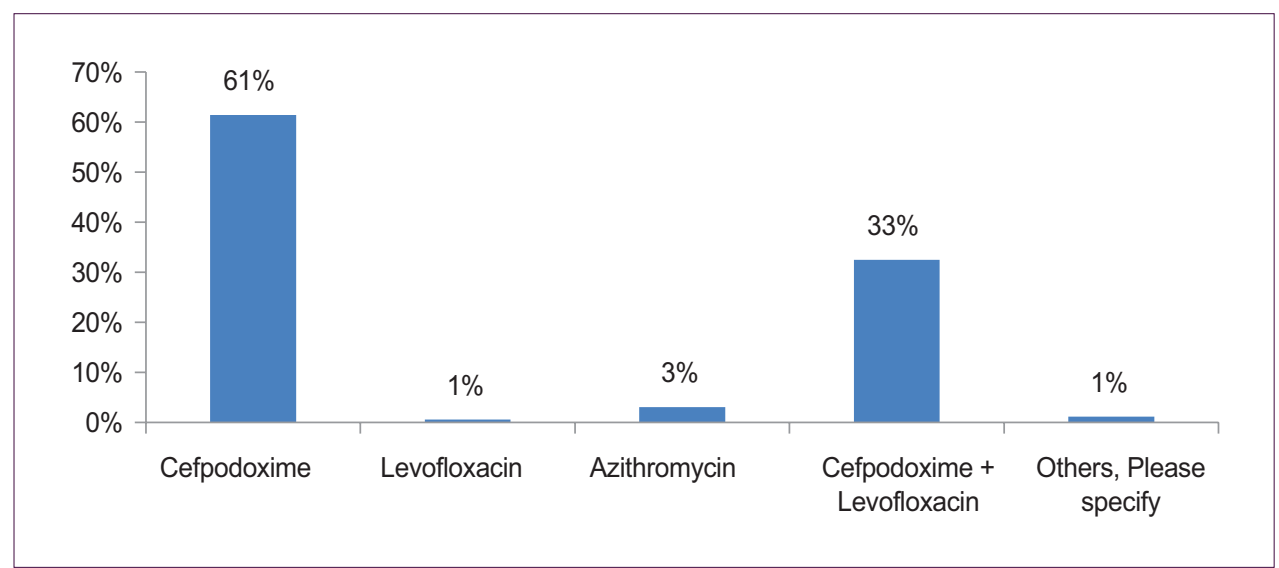

Figure 2: Preferred choice of cephalosporin in as mono or combination therapy in upper respiratory tract infection.

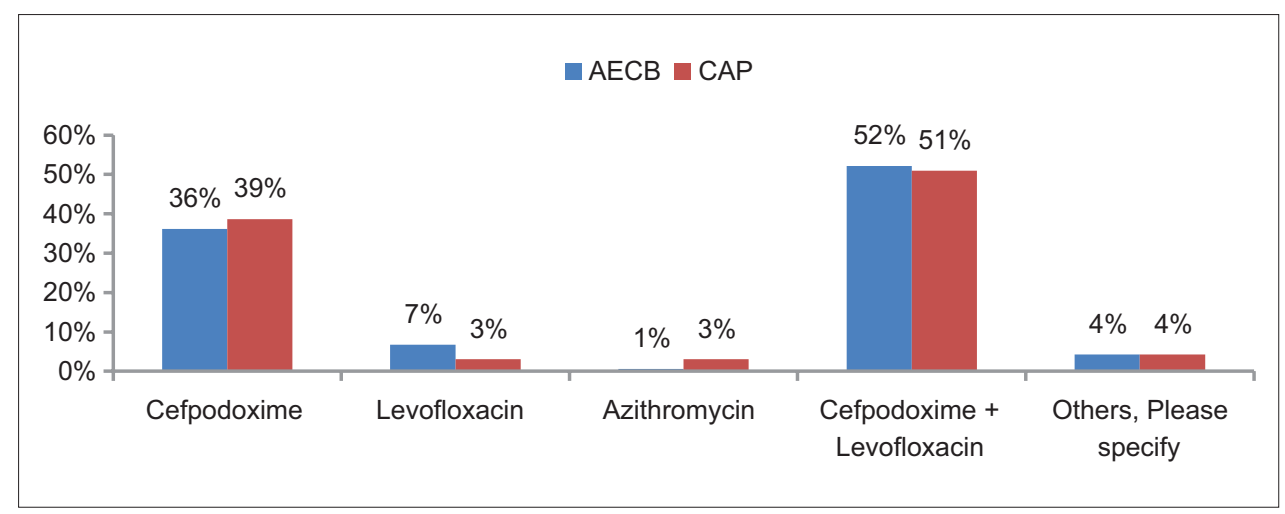

Figure 3: Preferred antibiotics in lower respiratory tract infections. 


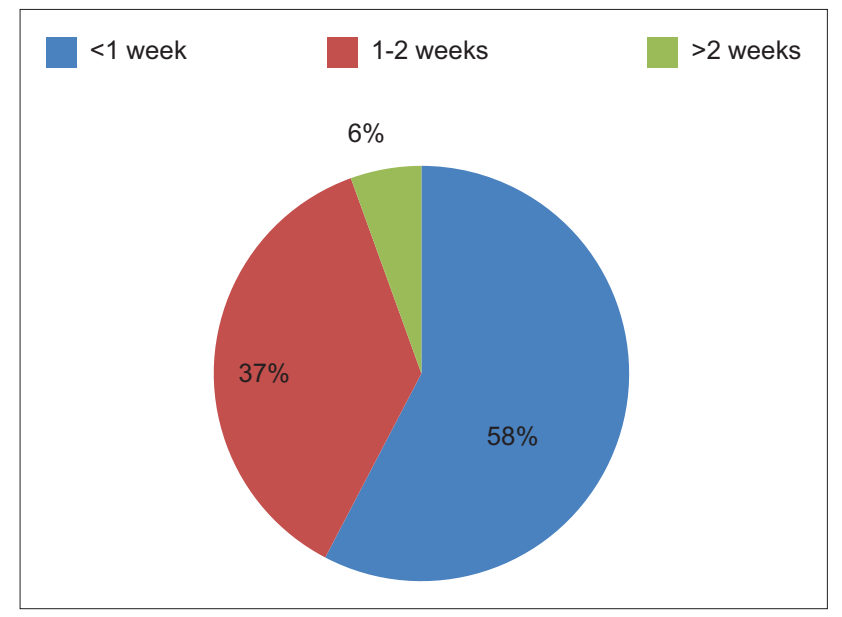

Figure 4: Duration of lower respiratory tract infections.

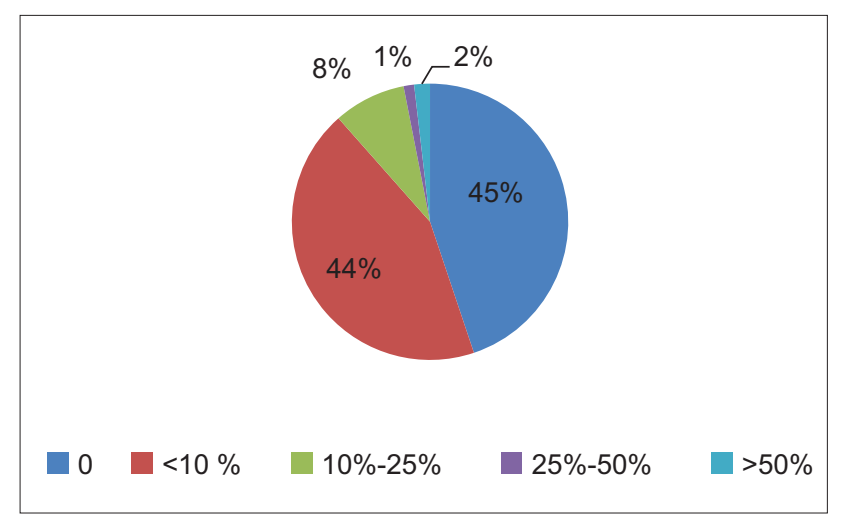

Figure 5: Preference to prescribe oral corticosteroids in acute exacerbation chronic obstructive pulmonary disease.

shown in Figure 2, followed by a fixed drug combination (FDC) of cefpodoxime and levofloxacin, This was followed by the preference of macrolide, i.e., azithromycin and least preference was given levofloxacin as monotherapy. Clinicians also prefer another FDC of cefpodoxime and ofloxacin, however, this choice was limited.

For the management of LRTI, there was a strong preference to FDC of cefpodoxime and levofloxacin as shown in Figure 3. Other preferred molecules were FDC of cefpodoxime + azithromycin and clarithromycin and amoxyclav. However, the number was very limited.

About 58\% of clinicians recommended cefpodoxime and levofloxacin combination therapy duration in LRTI to be of $\leq 1$ week as shown in Figure 4 . $>2$ weeks of antibiotic therapy was rarely preferred by clinicians, as these severe cases were advised indoor hospitalization to prevent relapse of disease and avoid future complications.

In the management of $\mathrm{AECB}$, use of oral corticosteroids is found to be very limited in real time clinical settings in India. Only $2 \%$ of the clinicians prefer frequent use $(>50 \%)$ of oral corticosteroids (OCS) in patients. $45 \%$ of the treating clinicians preferred antibiotics as shown in Figure 5.

\section{DISCUSSION}

Decisions regarding the antibiotic prescribing are made with consideration of patient-level risk/benefit evaluation. Antibiotics are frequently prescribed for ARIs, presumably to avoid any risk of progression to serious bacterial illness. Numerous practice guidelines ${ }^{3-5}$ recommend antibiotic treatment for ARIs, to achieve better clinical results and avoid complications. Available literature on antimicrobial use abroad and in India bears testimony to the widespread concern about the appropriate use of these agents. ${ }^{6,7}$ Monitoring of antimicrobial use and knowledge of prescription habits are some of the strategies recommended to contain resistance to antimicrobials. ${ }^{8}$ Various studies have justify the role of antibiotics including $\beta$-lactams/ $\beta$-lactamase inhibitors ${ }^{9-12}$ quinolones, ${ }^{13-15}$ macrolides ${ }^{16-18}$ as a monotherapy, or as a combination antibiotic therapy.

This survey was conducted to assess the in-clinic preference of oral antimicrobials for the management of ARIs in outpatient department settings. The findings are at par with the international and national publications, which recommend the use of monotherapy for the management of acute upper RTI. This survey reveals that for the management of tonsillitis and pharyngitis the preferred choice of antibiotic is cefpodoxime among cephalosporins in real-time clinical settings. This preference is probably due to better clinical efficacy and safety of cefpodoxime. Another probable reason is possibly related to its close relation of penicillin use with minimal possible.

Review of clinical studies also indicates the clinical efficacy of cefpodoxime wherein $100 \%$ clinical cure has been achieved ${ }^{19,20}$ along with $100 \%$ bacterial eradication. ${ }^{21}$ It was also noted that in case the severity of symptoms in the patients, clinicians preferred combination therapy of cefpodoxime and levofloxacin. Preference of this FDC may be related better clinical outcomes in severe cases and lesser of gastrointestinal related side effects.

Initial duration of therapy in lower RTI remains to be $\leq 1$ week by most of the treating physicians (58\%). This is probably due to the reasons like the cost of therapy, level of education of the patients/relatives, and preference of clinicians. The concept of complete cure is yet to be established with the Indian population. India continues to be a country with low per capita income and low literacy. As a result patients intend to spend less on medicines and prefer taking medicine only for the symptomatic relief of the disease. Most of the clinicians in India also recommend the initial prescription up to a period of $\leq 1$ week as they seek follow-up after 1 week of prescribed therapy. Patients with little or no symptom relief are either extended therapy for another 1-2 weeks or are advised admission. 
In the management of AECB, use of OCS has been found to be very limited among the clinicians in India. $45 \%$ of the treating clinicians prefer use of antibiotics only and wide use of OCS is limited to only $11 \%$ of the clinicians while fully exploring the potential for inhalers therapies in concomitant asthma and chronic obstructive pulmonary disease (COPD).

\section{CONCLUSION}

This survey showed that the in-clinic preference of cefpodoxime as an empirical antibiotic therapy is being observed by the clinicians in the management of upper RTI in particular for tonsillitis in the out-patient department. While treating lower RTI, i.e., CAP and AECB the preference shifts to combination therapy of cefpodoxime and levofloxacin. Use of oral corticosteroids in acute exacerbation of COPD is not preferred by Indian clinicians in the out-patient department. Cefpodoxime and its combinations have been found to be useful and preferred choice by the clinicians among the cephalosporins in Indian outpatient settings.

Funding: No funding sources

Conflict of interest: None declared

Ethical approval: Not required

\section{REFERENCES}

1. S KI, Chandy SJ, Jeyaseelan L, Kumar R, Suresh S. Antimicrobial prescription patterns for common acute infections in some rural and urban health facilities of India. Indian J Med Res. 2008;128(2):165-71.

2. Linder JA, Bates DW, Lee GM, Finkelstein JA. Antibiotic treatment of children with sore throat. JAMA. 2005;294(18):2315-22.

3. Chow AW, Benninger MS, Brook I, Brozek JL, Goldstein EJ, Hicks LA, et al. IDSA clinical practice guideline for acute bacterial rhinosinusitis in children and adults. Clin Infect Dis. 2012;54(8):e72-e112.

4. Wong DM, Blumberg DA, Lowe LG. Guidelines for the use of antibiotics in acute upper respiratory tract infections. Am Fam Physician. 2006;74(6):956-66.

5. Global Strategy for Asthma Management and Prevention. National Institutes of Health: National Heart, Lung, and Blood Institute. Washington, D.C: Bethesda, MD: National Institutes of Health; 2014.

6. Osih RB, McGregor JC, Rich SE, Moore AC, Furuno JP, Perencevich EN, et al. Impact of empiric antibiotic therapy on outcomes in patients with Pseudomonas aeruginosa bacteremia. Antimicrob Agents Chemother. 2007;51(3):839-44.

7. Srishyla MV, Rani MA, Venkataraman BV. Drug utilization of antimicrobials in the in-patient setting of a tertiary hospital. Indian J Pharmacol. 1994;26:282-7.

8. Badar VA, Navale SB. Study of prescribing pattern of antimicrobial agents in medicine intensive care unit of a teaching hospital in Central India. J Assoc Physicians India. 2012;60:20-3.

9. White AR, Kaye C, Poupard J, Pypstra R, Woodnutt G, Wynne B. Augmentin (amoxicillin/clavulanate) in the treatment of community-acquired respiratory tract infection: a review of the continuing development of an innovative antimicrobial agent. J Antimicrob Chemother. 2004;53 Suppl 1:i3-20.

10. Schreiner A. Beta-lactam antibiotics in lower respiratory tract infections. Scand J Infect Dis Suppl. 1984;42:129-34.

11. Paterson DL, Bonomo RA. Extended-spectrum betalactamases: a clinical update. Clin Microbiol Rev. 2005;18(4):657-86.

12. Drawz SM, Bonomo RA. Three decades of beta-lactamase inhibitors. Clin Microbiol Rev. 2010;23(1):160-201.

13. Ritrovato CA, Deeter RG. Respiratory tract penetration of quinolone antimicrobials: a case in study. Pharmacotherapy. 1991;11(1):38-49.

14. Cazzola M, Blasi F, Terzano C, Matera MG, Marsico SA. Delivering antibacterials to the lungs: considerations for optimizing outcomes. Am J Respir Med. 2002;1(4):261-72.

15. Grossman RF. The role of fluoroquinolones in respiratory tract infections. J Antimicrob Chemother. 1997;40 Suppl A:59-62.

16. Wierzbowski AK, Hoban DJ, Hisanaga T, DeCorby M, Zhanel GG. The use of macrolides in treatment of upper respiratory tract infections. Curr Allergy Asthma Rep. 2006;6(2):171-81.

17. Min JY, Jang YJ. Macrolide therapy in respiratory viral infections. Mediators Inflamm. 2012;2012:649570.

18. OrtqvistA. Treatment of community-acquired lower respiratory tract infections in adults. Eur Respir J Suppl. 2002;36:40s-53.

19. Portier H, Chavanet P, Gouyon JB, Guetat F. Five day treatment of pharyngotonsillitis with cefpodoxime proxetil. J Antimicrob Chemother. 1990;26 Suppl E:79-85.

20. Portier H, Chavanet P, Ichou F, The Multicentre Group. Five day antibiotherapy in presumed bacterial acute tonsillitis: a comparative study of cefpodoxime proxetil vs cefuroxime axetil. Poster presented at the International Congress of Infectious Disease, Montreal, July 15-19, 1990.

21. Kline NE, Kline MW. Cefpodoxime proxetil versus penicillin $\mathrm{V}$ in the treatment of streptococcal pharyngitis in children. Curr Ther Res. 1991;49:807-13.

doi: $10.18203 / 2319-2003 . i j b c p 20150037$

Cite this article as: Sobti V, Krishnaprasad K, Bhargava A.

An epidemiological survey to assess the clinical use of cephalosporins in community-acquired respiratory tract infections. Int J Basic Clin Pharmacol 2015;4:547-50. 